\title{
Comparison of 2-octyl cyanoacrylate skin adhesive and interrupted polypropylene sutures for wound closure in total ankle arthroplasty
}

\author{
Gun-Woo Lee, Woo Kyoung Kwak and Keun-Bae Lee* ${ }^{*}$
}

\begin{abstract}
Background: Adhesive skin materials have increasingly been used in orthopedic surgery. We aimed to compare the efficacy and safety of skin adhesive (2-octyl cyanoacrylate and polymer mesh, Dermabond Prineo) and interrupted polypropylene sutures for wound closure in patients undergoing total ankle arthroplasty (TAA).

Methods: We prospectively enrolled 107 consecutive patients (108 ankles) undergoing TAA and divided them into two groups: skin adhesive group (36 ankles) and suture group (72 ankles). The primary outcome assessment included wound complications and patient satisfaction for wound cosmesis. The secondary outcome assessment included duration of surgery, length of hospital stay, and the Ankle Osteoarthritis Scale (AOS) pain and disability score.

Results: There was one case of allergic contact dermatitis, three cases of wound dehiscence, and one case of superficial surgical site infection in the skin adhesive group. Among them, one case each with allergic contact dermatitis and wound dehiscence finally progressed to deep surgical site infection. Three cases of wound dehiscence were also reported in the suture group; however, there was no case of surgical site infection. Patient satisfaction for wound cosmesis was significantly higher in the skin adhesive group than in the suture group $(p=0.001)$. There was no statistically significant difference between the groups in terms of secondary outcomes ( $p>0.05)$.
\end{abstract}

Conclusions: Although the use of Dermabond Prineo showed better patient satisfaction for wound cosmesis, it showed significantly high wound complication rates and no other clinical benefits compared to interrupted polypropylene suture in TAA. Our results suggest that awareness of the possibility of wound complications is necessary when Dermabond Prineo is used in TAA.

Keywords: Total ankle arthroplasty, Skin adhesive, Skin suture, Skin closure, Wound complication

\section{Introduction}

Total ankle arthroplasty (TAA) has been steadily developed while overcoming the drawbacks of the past and is widely performed as a primary treatment for end-stage ankle arthritis [1-9]. Wound closure is an important final step for good cosmesis and minimizing surgical site infection [10]. There is still no consensus about the best

*Correspondence: kbleeos@jnu.ac.kr

Department of Orthopedic Surgery, Chonnam National University Medical School and Hospital, 42 Jebongro, Donggu, Gwangju 61469, Republic of Korea method of closing wounds in orthopedic surgery [11, 12]; however, skin suture methods consume a marked time during surgery with an added inconvenience of removal after healing [13]. In recent times, noninvasive skin closure methods including skin adhesive and zipper-like dressing are being widely used to minimize discomfort and scar formation [14-21].

Skin adhesive materials have become increasingly popular in elective orthopedic surgery [14, 16, 18-20, 22, 23]. The Dermabond Prineo topical skin adhesive (Ethicon, Somerville, NJ) consists of a 2-octyl cyanoacrylate liquid and a self-adhering polyester mesh with benzalkonium original author(s) and the source, provide a link to the Creative Commons licence, and indicate if changes were made. The images or other third party material in this article are included in the article's Creative Commons licence, unless indicated otherwise in a credit line to the material. If material is not included in the article's Creative Commons licence and your intended use is not permitted by statutory regulation or exceeds the permitted use, you will need to obtain permission directly from the copyright holder. To view a copy of this licence, visit http://creativecommons.org/licenses/by/4.0/. The Creative Commons Public Domain Dedication waiver (http://creativeco mmons.org/publicdomain/zero/1.0/) applies to the data made available in this article, unless otherwise stated in a credit line to the data. 
chloride. This product is known to reduce the risk of early infection after surgery by providing a water-tight seal to minimize wound drainage and an effective barrier to microorganisms [16].

Previous studies have reported the superiority of Dermabond Prineo skin adhesive in terms of cosmetic outcomes, lesser wound discharge, cost-effectiveness, and shorter length of hospital stay when used in hip and knee arthroplasty [15, 19, 20, 22, 23]. Despite these advantages and convenience in use, several recent studies have reported complications associated with its use; these are being increasingly reported as the use of the material has steadily increased. Most of these studies have highlighted concerns like allergic reactions following the use of Dermabond Prineo [10, 24-29]. This reaction is similar to postoperative infection and is difficult to distinguish; additionally, reaction symptoms are known to vary from mild to severe. Furthermore, in case of severe skin breakdown, it is highly likely to cause deep surgical site infection $[10,24]$.

Literature search showed no previous studies have evaluated the efficacy and safety of Dermabond Prineo as wound closure material in TAA. Thus, our study aimed to compare wound complication rate, duration of surgery, length of hospital stay, and clinical outcomes between Dermabond Prineo and interrupted polypropylene sutures used for wound closure in patients undergoing TAA.

\section{Materials and methods Patient selection}

This study was approved by the institutional review board of our hospital. Between January 2016 and December 2018, 108 consecutive patients (111 ankles) underwent primary TAA using the mobile-bearing HINTEGRA prostheses (Newdeal, Lyon, France/Integra Lifesciences, Plainsboro, NJ USA). All operations were performed by one surgeon with experience of over 200 TAA.

The indication for primary TAA included end-stage ankle arthritis in patients with good general conditions, including well-controlled diabetes, good bone stock, and normal neurovascular status. The inclusion criteria for this study were symptomatic end-stage ankle osteoarthritis or rheumatoid arthritis with a minimum follow-up of 12 months after TAA. We excluded patients with hemophilic arthropathy and gouty arthritis of the ankle joint.

Finally, 107 patients (108 ankles) were enrolled and divided into two groups according to the method of wound closure. For the first half of the study period (from January 2016 to June 2017), 2-octyl cyanoacrylate and polymer mesh (Dermabond Prineo) were used in the skin adhesive group (36 patients, 36 ankles), and interrupted polypropylene suture was used during the second half of the study period from (July 2017 to December 2018) in the suture group (61 patients, 62 ankles).

\section{Surgical technique and removal of skin closure materials}

All TAA were performed through the anterior longitudinal approach between the extensor hallucis longus and tibialis anterior tendon under general or spinal anesthesia. Distal tibial and talar dome resections were performed perpendicular to the mechanical axis of the tibia. After the medial, lateral, and posterior talar cuts, appropriately sized prostheses were implanted. If necessary, concomitant bony or ligamentous procedures were performed to achieve neutral hindfoot alignment and ligamentous balance.

In all patients, the anterior joint capsule and extensor retinaculum were repaired using 1-0 braided absorbable sutures (Vicryl, Ethicon, Somerville, NJ). The subcutaneous layer was repaired using 2-0 monofilament absorbable suture (Monosyn, B. Braun, Rubi, Spain). For skin closure, Dermabond Prineo was applied, followed by air drying for $1 \mathrm{~min}$ in the skin adhesive group, while 3-0 nonabsorbable polypropylene (Prolene, Ethicon, Somerville, NJ) horizontal mattress sutures were performed in the suture group. Subsequently, a compressive dressing and posterior short leg splint were applied in neutral ankle position. All skin closure materials were removed between 10 and 12 days after surgery. Particularly, for the removal of Dermabond Prineo, petroleum jelly (Vaseline, Unilever) was applied to loosen it, and then it was carefully peeled off from the skin. After removing suture materials, the patients were allowed to begin a range-ofmotion exercise. Four weeks after surgery, the patient was instructed to begin progressive weight-bearing by wearing an ankle-foot orthosis. Full weight-bearing ambulation without orthosis began 6 to 8 weeks after surgery.

\section{Clinical evaluation}

Clinical assessment included the wound complications, patient satisfaction for wound cosmesis, duration of surgery, hospital stay, and Ankle Osteoarthritis Scale (AOS) pain and disability score. The incidence of wound complications and patient satisfaction for wound cosmesis were the primary assessment parameters. Wound complications were evaluated during hospitalization or at the outpatient clinic 4 weeks after surgery, and the satisfaction survey was conducted at least 12 months after surgery. The wound complications were subdivided into allergic contact dermatitis (ACD), wound dehiscence, and surgical site infection (SSI). The appearance of an eczematous eruption or blister at the suture area or the area where the skin adhesive mesh was attached was classified as ACD [29]. The wound dehiscence is defined as a partial or total separation of previously approximated wound 
edges due to a failure of proper wound healing [30]. The SSI was classified into superficial or deep infection based on the extent of infection [31]. Patient satisfaction was surveyed through a questionnaire administered to the patients and categorized into 'very satisfied,' 'satisfied,' 'as expected', and 'dissatisfied.'

The secondary assessment included duration of surgery, length of hospital stay, and functional outcomes. Functional outcome was evaluated before surgery, at 6 and 12 months after surgery, and every year thereafter by AOS pain and disability score, which was reliable and validated for ankle joint-specific outcome [32].

\section{Statistical analyses}

Data were analyzed using SPSS (version 23.0, IBM Corp., Armonk, NY USA). Descriptive statistics were calculated using the standard formulae. Kolmogorov-Smirnov test was used to verify the normal distribution of data variables. An independent $t$ test was used to analyze the differences between the groups for normally distributed continuous variables; else, Mann-Whitney $U$ test was used for comparing variables that were not normally distributed. For the categorical variables, Chi-square or Fisher's exact tests were used to analyze the differences.
All statistical analyses were reviewed by a statistician, and a $p$-value $<0.05$ was considered significant.

\section{Results}

The information of patients in each group is shown in Table 1 . There were no significant differences in age, sex, presence of diabetes, number of current smokers and antithrombotic drug users, body mass index (BMI), preoperative diagnosis, follow-up period, and other medical conditions $(p>0.05)$ between the groups.

The incidence of wound complications is shown in Table 2. The overall number of ankles with wound complications was $5(13.9 \%)$ of 36 cases in the skin adhesive group and $2(2.8 \%)$ of 72 cases in the suture group $(p=0.04)$. There was one case of allergic contact dermatitis, three cases of wound dehiscence, and one case of superficial surgical site infection in the skin adhesive group. Two cases of wound dehiscence were also reported in the suture group; however, there was no case of surgical site infection.

One case of ACD and 3 cases of SSI were seen in the skin adhesive group, whereas these complications did not occur in the suture group (Fig. 1). Among them, one case with superficial SSI improved with antibiotic treatment and wound care without further surgery. However,

Table 1 Patient demographics

\begin{tabular}{|c|c|c|c|}
\hline & Skin adhesive group ( $N=36$ ankles) & Suture group ( $N=72$ ankles) & $p$-value* \\
\hline Age (years)† & $67.7 \pm 7.1(53$ to 80$)$ & $67.1 \pm 8.3(49$ to 86$)$ & 0.731 \\
\hline $\operatorname{Sex} \ddagger$ & & & 0.785 \\
\hline Male & $18(50.0 \%)$ & $33(45.8 \%)$ & \\
\hline Female & $18(50.0 \%)$ & $39(54.2 \%)$ & \\
\hline Diabetesł & $6(16.7 \%)$ & $13(18.1 \%)$ & 0.726 \\
\hline Current smoker $\neq$ & $2(5.6 \%)$ & $8(11.1 \%)$ & 0.491 \\
\hline Antithrombotic drug use $\neq$ & $4(11.1 \%)$ & $8(11.1 \%)$ & 0.999 \\
\hline $\operatorname{BMI}\left(\mathrm{kg} / \mathrm{m}^{2}\right) \dagger$ & $26.5 \pm 3.7(18.1$ to 34.3$)$ & $25.4 \pm 2.9(18.6$ to 32.0$)$ & 0.163 \\
\hline Hemoglobin (g/dL) & $13.9 \pm 1.4(11.1$ to 17.2$)$ & $13.7 \pm 1.4(9.3$ to 17.7$)$ & 0.484 \\
\hline Albumin (g/dL) & $4.4 \pm 0.3(3.8$ to 5.1$)$ & $4.4 \pm 0.3(3.7$ to 5.2$)$ & 0.876 \\
\hline Platelets $\left(10^{3} / \mu \mathrm{L}\right)$ & $236.2 \pm 61.3(121.0$ to 372.0$)$ & $239.7 \pm 60.9(141.0$ to 445.0$)$ & 0.794 \\
\hline Diagnosisł & & & 0.286 \\
\hline Primary osteoarthritis & $21(58.3 \%)$ & $39(54.2 \%)$ & \\
\hline \multicolumn{4}{|l|}{ Posttraumatic osteoarthritis } \\
\hline Postfracture & - & $7(9.7 \%)$ & \\
\hline Recurrent ankle sprain & $14(38.9 \%)$ & $24(33.3 \%)$ & \\
\hline Rheumatoid arthritis & $1(2.8 \%)$ & $2(2.8 \%)$ & \\
\hline Follow-up (month)† & $38.7 \pm 7.1$ (18 to 48$)$ & $35.3 \pm 10.7$ (20 to 61$)$ & 0.069 \\
\hline
\end{tabular}

Abbreviations: $B M I$, body mass index

* The independent $t$ test was used to analyze differences in age, BMI, hemoglobin, albumin, platelets, and follow-up duration. The Chi-square or Fisher's exact test was used to analyze differences in sex, diabetes, current smoker, antithrombotic drug use, and preoperative diagnosis between the groups. A $p$-value of $<0.05$ was considered significant

${ }^{\dagger}$ The values are given as the mean \pm standard deviation, with the range in parentheses

${ }^{\ddagger}$ The values are given as the number of ankles, with the percentage in parentheses 
Table 2 Wound complications following total ankle arthroplasty according to the wound closure method

\begin{tabular}{llll}
\hline & $\begin{array}{l}\text { Skin Adhesive } \\
\text { Group }(\boldsymbol{N}=\mathbf{3 6} \\
\text { ankles) }\end{array}$ & $\begin{array}{l}\text { Suture group } \\
(\mathbf{N = 7 2} \text { ankles) }\end{array}$ & $\boldsymbol{p}$-value† \\
\hline None & $31(86.1 \%)$ & $70(97.2 \%)$ & 0.040 \\
$\begin{array}{l}\text { Allergic contact } \\
\text { dermatitis }\end{array}$ & $1(2.8 \%)$ & - & 0.333 \\
$\begin{array}{l}\text { Wound dehiscence } \\
\text { Surgical site infection }\end{array}$ & $3(8.3 \%)$ & $2(2.8 \%)$ & 0.331 \\
$\quad$ Superficial & $1(2.8 \%)$ & - & 0.035 \\
\multicolumn{1}{c}{ Deep } & $2^{\ddagger}(5.6 \%)$ & - & \\
\hline
\end{tabular}

The values are given as the number of ankles, with the percentage in parentheses

${ }^{\dagger}$ Fisher's exact test was used to analyze the intergroup differences. A $p$-value of $<0.05$ was considered significant

‡ The overall number of ankles with wound complications was 5 (13.9\%) of 36 cases in the skin adhesive group. Among them, one case each of allergic contact dermatitis and wound dehiscence progressed to deep infection

one case, each of ACD and wound dehiscence progressed to deep SSI. The patient who developed ACD followed by deep SSI recovered after repeated debridement and polyethylene liner exchange without implant removal; however, a local flap surgery was performed for the accompanying soft tissue necrosis. The patient with deep SSI due to wound dehiscence was successfully treated by revision TAA in a two-stage procedure using an antibiotic-impregnated cement spacer. The 4 cases of wound dehiscence ( 2 in the skin adhesive group, 2 in the suture group) healed with daily dressing and prolonged antibiotic use. There was a case with full incisional dehiscence, which did not occur after skin suture in the skin adhesive group (Fig. 2).

Regarding patient satisfaction for wound cosmesis, 34 $(94.4 \%)$ of 36 patients in the skin adhesive group reported that they were 'very satisfied' or 'satisfied,' and there was a significant difference compared to the responses in the suture group (Table 3 ).

The comparison of duration of surgery, length of hospital stay, and AOS pain disability score is shown in Table 4. There was no statistically significant difference in the duration of surgery and length of hospital stay between the two groups $(p>0.05)$. In terms of the functional outcomes, there were no significant intergroup differences in the AOS pain, and disability scores at the final follow-up $(p>0.05)$.

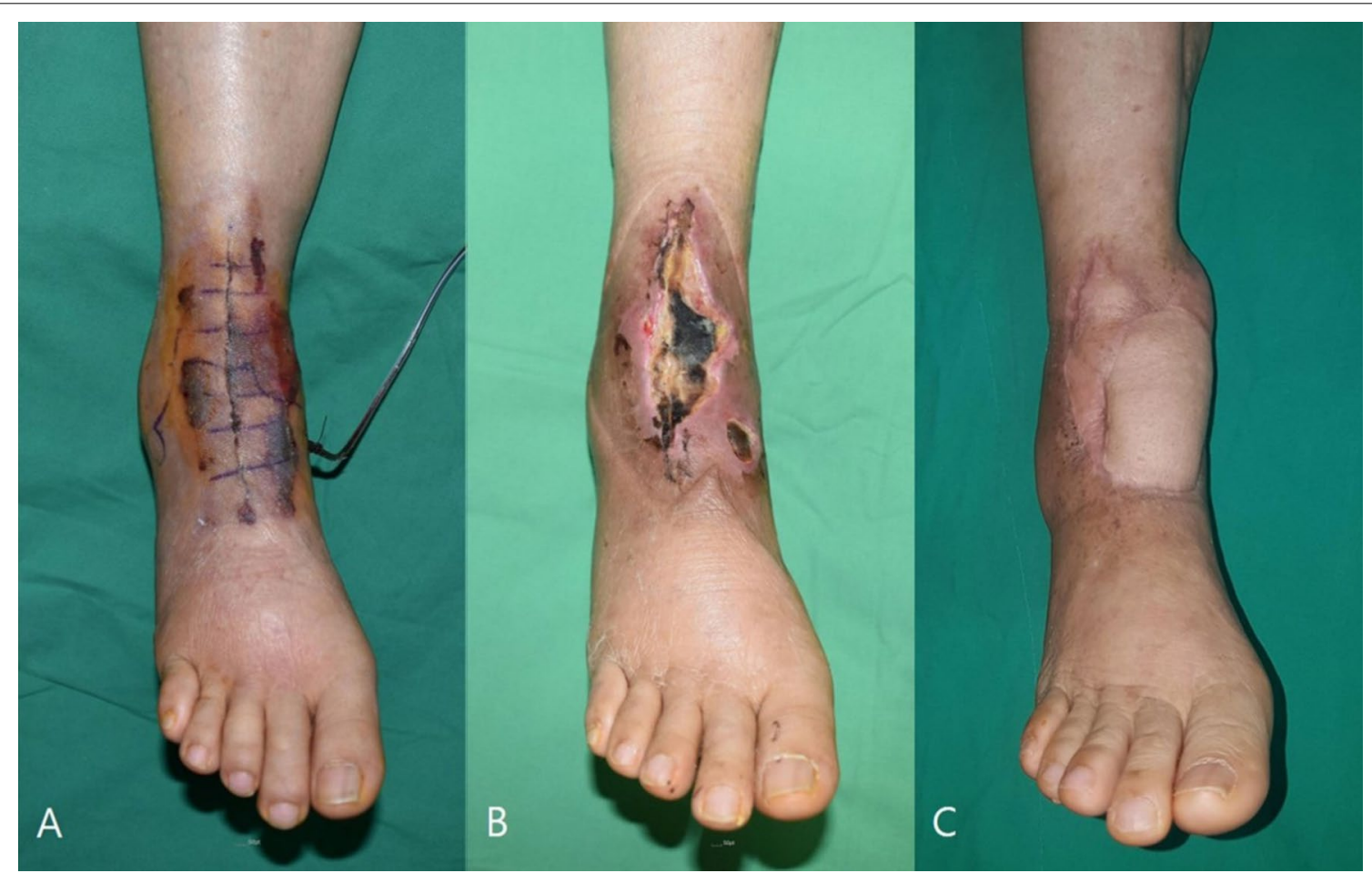

Fig. 1 a A 64-year-old female developed allergic contact dermatitis (ACD) after applying Dermabond Prineo for wound closure. $\mathbf{b}$ Despite wound care using negative pressure wound therapy (NPWT) and prolonged intravenous antibiotic treatment, she developed deep surgical site infection (SSI) with wound necrosis. c The patient recovered after repeated debridement and polyethylene liner exchange without implant removal; in addition, a local flap surgery was performed for the accompanying soft tissue necrosis 


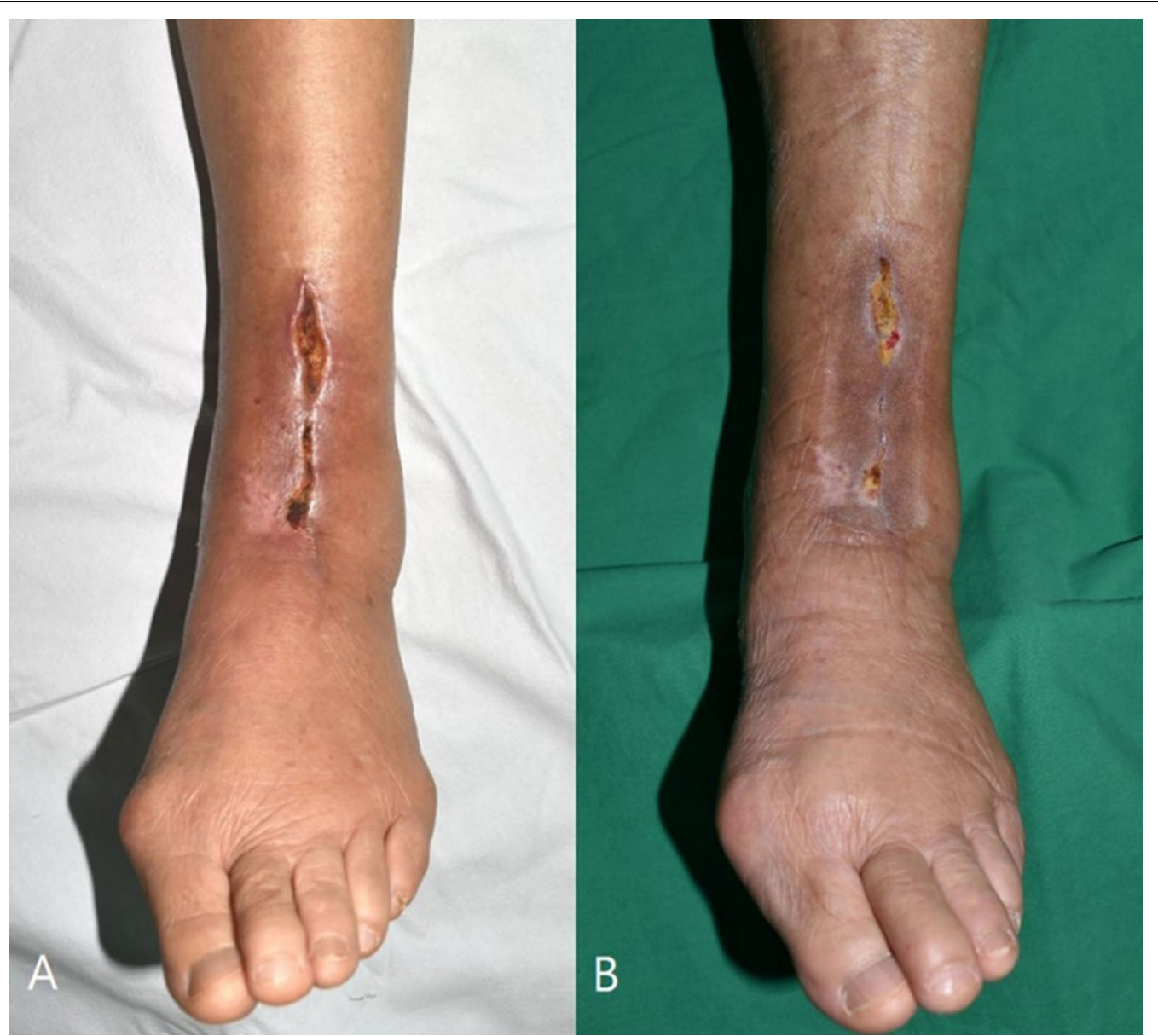

Fig. 2 a A 75-year-old female patient developed full incisional wound dehiscence after wound closure with Dermabond Prineo. b The wound recovered by applying negative pressure wound therapy (NPWT) without the need for further surgery

Table 3 Patient satisfaction for wound cosmesis following total ankle arthroplasty according to the wound closure method

\begin{tabular}{clll}
\hline & $\begin{array}{l}\text { Skin adhesive } \\
\text { group }(\boldsymbol{N}=\mathbf{3 6} \\
\text { ankles) }\end{array}$ & $\begin{array}{l}\text { Suture group } \\
(\boldsymbol{N}=\mathbf{7 2} \text { ankles) }\end{array}$ & $\boldsymbol{p}$-valuet \\
\hline $\begin{array}{c}\text { Level of satisfaction } \\
\text { Very satisfied }\end{array}$ & $30(83.3 \%)$ & $32(44.4 \%)$ & 0.001 \\
Satisfied & $4(11.1 \%)$ & $32(44.4 \%)$ & \\
As expected & - & $8(11.2 \%)$ & \\
Dissatisfied & $2(5.6 \%)$ & - & \\
\hline
\end{tabular}

The values are given as the number of ankles, with the percentage in parentheses

${ }^{\dagger}$ Fisher's exact test was used to analyze the intergroup differences. A $p$-value of $<0.05$ was considered significant

\section{Discussion}

To our knowledge, this is the first study to evaluate the efficacy and safety of Dermabond Prineo for skin closure after TAA. The most important finding of this study is that the use of Dermabond Prineo showed a significantly high rate of overall wound complications and did not show any other benefits in terms of duration of surgery, length of hospital stay, and clinical outcomes.

In recent times, skin adhesive materials, including Dermabond Prineo, are widely used in elective orthopedic surgery due to various advantages $[14,15,18-22$, 33]. These benefits are still debatable and recent studies have repeatedly reported concerns about wound complications following the use of a skin adhesive material composed of 2-octyl cyanoacrylate [27, 34-37]. Almustafa et al. investigated the risk factors for SSI by analyzing 2,100 cases of primary total knee arthroplasty. The use of 2-octyl cyanoacrylate skin glue for wound closure was identified as a risk factor for SSI following total knee arthroplasty [38]. With respect to ankle surgery, Park et al. demonstrated that the use of 2-octyl cyanoacrylate topical skin adhesive (Surgiseal, Adhezion Biomedical LLC, Wyomissing, PA, USA) for wound closure was effective and safe with high patient 
Table 4 Other clinical outcomes following total ankle arthroplasty according to the wound closure method

\begin{tabular}{|c|c|c|c|}
\hline & Skin adhesive group ( $N=36$ ankles) & Suture group ( $N=72$ ankles) & $p$-value* \\
\hline Duration of surgery (min) $\dagger$ & $113.4 \pm 23.8$ (70 to 160$)$ & $114.1 \pm 22.1(75$ to 160$)$ & 0.918 \\
\hline Hospital stay (day)‡ & $11.0(8.0$ to 14.0$)$ & $13.0(9.0$ to 15.0$)$ & 0.239 \\
\hline \multicolumn{4}{|l|}{ AOS pain scoret } \\
\hline Preoperative & $58.0 \pm 14.3$ (33.3 to 85.7$)$ & $54.7 \pm 17.1(21.4$ to 82.9$)$ & 0.437 \\
\hline Final & $29.2 \pm 20.4$ (0.0 to 80.0$)$ & $24.4 \pm 18.0$ (0.0 to 71.4$)$ & 0.288 \\
\hline \multicolumn{4}{|l|}{ AOS disability score $†$} \\
\hline Preoperative & $68.8 \pm 16.1(21.1$ to 95.6$)$ & $71.3 \pm 16.9$ (34.4 to 93.3$)$ & 0.558 \\
\hline Final & $37.6 \pm 18.2(6.7$ to 80.0$)$ & $31.0 \pm 19.4$ (0.0 to 82.2$)$ & 0.148 \\
\hline
\end{tabular}

Abbreviations: AOS, Ankle Osteoarthritis Scale

${ }^{*}$ The independent $t$ test was used to analyze differences in duration of surgery, AOS pain and disability scores. The Mann-Whitney $U$ test was used to analyze differences in hospital stay. A $p$-value of $<0.05$ was considered significant

${ }^{\dagger}$ The values are given as the mean \pm standard deviation, with the range in parentheses

${ }^{\ddagger}$ The values are given as the median, with the interquartile range in parentheses

satisfaction after ankle fracture surgery [18]. However, they also reported that the attention was needed because the statistical power of the complication was insufficient.

In this study, there was a case of full incisional dehiscence, which did not occur in the suture group. We assumed that tension around the entire wound might have led to the occurrence of full wound dehiscence. In the case of a skin suture, the tension is applied focally around the skin through which the thread passes; however, the tension is applied to the wide area of the entire wound when skin adhesive is used. Other previous studies have also described that increasing tissue tension can lead to superficial skin damage by shearing the skin when the skin adhesive material was used [38]. Furthermore, there were two cases of deep SSI in the skin adhesive group, of which one each progressed from $\mathrm{ACD}$ and wound dehiscence. We assumed that the relatively thin soft tissue envelope of the ankle joint compared to that of the hip or knee joint might increase vulnerability to the development of SSI when $\mathrm{ACD}$ or wound dehiscence occurs.

Based on our experience of wound complications in the skin adhesive group, we have discontinued the use of Dermabond Prineo for wound closure in TAA. Since there are not many studies on the use of Dermabond Prineo in ankle surgery, it is too early to conclude that its use increases the rates of wound complication and SSI. However, it has been frequently reported that the constituents of Dermabond Prineo induce allergic reactions. These can lead to ACD or wound dehiscence and can cause critical complications such as deep SSI [10, 25, 27$29,34-37,39-42]$. ACD is more likely to develop when the skin is in prolonged contact with the allergen or when the amount of allergen is high [36, 37, 39].
There is still no established method for the prophylaxis of ACD after the use of Dermabond Prineo. According to previous reports, patch testing for Dermabond Prineo glue or polyester mesh has been known to be useful to identify the patient who may have allergenic reactions postoperatively [29]. Bulky occlusive dressings after TAA can increase the absorption of allergens, and water or a humid environment can cause depolymerization to create a strong sensitizer, a monomer. Thus, dry permeable dressing is recommended to minimize an allergic reaction [34, 43, 44]. In addition, the application of incisional negative pressure wound therapy (NPWT) has been known to reduce the incidence of wound complications after TAA. However, the efficacy and safety of NPWT after the use of Dermabond Prineo have not yet been reported [45-47].

This study had several weaknesses. First, the sample size of both groups was small. This limited our ability to evaluate the safety of Dermabond Prineo. Second, we did not measure the time skin taken for closure separately and evaluated the cosmetic outcome by the objective wound score. Finally, we did not perform preoperative testing for other allergens that could cause skin complications. We use chlorhexidine for preoperative skin preparation, which is also known to be an allergen.

\section{Conclusion}

In conclusion, although the use of Dermabond Prineo showed better patient satisfaction for wound cosmesis, there was a significantly high rate of overall wound complications, and there were no other benefits in terms of duration of surgery, length of hospital stay, and clinical outcomes compared to those with the use of interrupted polypropylene suture in TAA. Our results suggest that careful vigilance is necessary when using Dermabond 
Prineo in TAA. Further studies with larger samples are necessary to determine the effect of Dermabond Prineo in wound closure.

\author{
Abbreviations \\ TAA: Total ankle arthroplasty; AOS: Ankle Osteoarthritis Scale; ACD: Allergic \\ contact dermatitis; SSI: Surgical site infection; BMI: Body mass index.
}

\section{Authors' contributions}

GW Lee conceived of the study and participated in its design and coordination and wrote the initial manuscript draft. KB Lee carried out the operations and revised manuscript. WK Kwak participated in collection and interpretation of the data. All authors read and approved the final manuscript.

\section{Funding}

This research was supported by grants from Chonnam National University Hospital Biomedical Research Institute (Grant No. BCRI20029).

\section{Availability of data and materials}

The datasets analyzed during the current study are not publicly available due to patient confidentiality.

\section{Declarations}

Ethics approval and consent to participate

This study was approved by Chonnam National University Hospital Institutional Review Board (IRB NO: CNUH-2021-025).

\section{Consent for publication}

Not applicable.

\section{Competing interests}

The authors declare that they have no competing interests.

Received: 31 August 2021 Accepted: 12 October 2021

Published online: 24 October 2021

\section{References}

1. Clough T, Bodo K, Majeed H, Davenport J, Karski M. Survivorship and long-term outcome of a consecutive series of 200 Scandinavian Total Ankle Replacement (STAR) implants. Bone Joint J. 2019;101-B(1):47-54.

2. Gougoulias N, Maffulli N. History of total ankle replacement. Clin Podiatr Med Surg. 2013;30(1):1-20.

3. Gougoulias N, Khanna A, Maffulli N. How successful are current ankle replacements?: a systematic review of the literature. Clin Orthop Relat Res. 2010;468(1):199-208.

4. Lee GW, Lee KB. Outcomes of total ankle arthroplasty in ankles with $>20^{\circ}$ of coronal plane deformity. J Bone Joint Surg Am. 2019;101(24):2203-11.

5. Vakhshori V, Sabour AF, Alluri RK, Hatch GF 3rd, Tan EW. Patient and practice trends in total ankle replacement and tibiotalar arthrodesis in the United States From 2007 to 2013. J Am Acad Orthop Surg. 2019;27(2):e77-84.

6. Saltzman CL, Mann RA, Ahrens JE, et al. Prospective controlled trial of STAR total ankle replacement versus ankle fusion: initial results. Foot Ankle Int. 2009;30(7):579-96.

7. Gougoulias NE, Khanna A, Maffulli N. History and evolution in total ankle arthroplasty. Br Med Bull. 2009;89:111-51.

8. Lee GW, Wang SH, Lee KB. Comparison of intermediate to long-term outcomes of total ankle arthroplasty in ankles with preoperative varus, valgus, and neutral alignment. J Bone Joint Surg Am. 2018;100(10):835-42.

9. Lee GW, Santoso A, Lee KB. Comparison of intermediate-term outcomes of total ankle arthroplasty in primary and ligamentous post-traumatic osteoarthritis. Foot Ankle Int. 2019;40(11):1273-81.

10. Pate RC, Neumeister MW. Severe wound complication due to prineo surgical dressing in shoulder hemiarthroplasty: a case report. JBJS Case Connect. 2020;10(1):e0306.
11. Daines BK, Dennis DA, Amann S. Infection prevention in total knee arthroplasty. J Am Acad Orthop Surg. 2015;23(6):356-64.

12. Heller S, Rezapoor M, Parvizi J. Minimising the risk of infection: a perioperative checklist. Bone Joint J. 2016;98-B(1 Suppl A):18-22.

13. Lee JC, Ishtihar S, Means JJ, Wu J, Rohde CH. In search of an ideal closure method: a randomized, controlled trial of octyl-2-cyanoacrylate and adhesive mesh versus subcuticular suture in reduction mammaplasty. Plast Reconstr Surg. 2018;142(4):850-6.

14. Carli AV, Spiro S, Barlow BT, Haas SB. Using a non-invasive secure skin closure following total knee arthroplasty leads to fewer wound complications and no patient home care visits compared to surgical staples. Knee. 2017;24(5):1221-6.

15. El-Gazzar Y, Smith DC, Kim SJ, et al. The use of dermabond ${ }^{\circledR}$ as an adjunct to wound closure after total knee arthroplasty: examining immediate post-operative wound drainage. J Arthroplasty. 2013;28(4):553-6.

16. Khurana A, Parker S, Goel V, Alderman PM. Dermabond wound closure in primary hip arthroplasty. Acta Orthop Belg. 2008;74(3):349-53.

17. Livesey C, Wylde V, Descamps S, et al. Skin closure after total hip replacement: a randomised controlled trial of skin adhesive versus surgical staples. J Bone Joint Surg Br. 2009;91(6):725-9.

18. Park YH, Song JH, Choi GW, Kim HJ. Comparison of 2-octyl cyanoacrylate topical skin adhesive and simple interrupted nylon sutures for wound closure in ankle fracture surgery. Foot Ankle Int. 2018;39(11):1283-9.

19. Siddiqui $M$, Bidaye $A, B$ aird $E$, et al. Wound dressing following primary total hip arthroplasty: a prospective randomised controlled trial. J Wound Care. 2016;25(1):40-5.

20. Sundaram K, Piuzzi NS, Patterson BM, Stearns KL, Krebs VE, Mont MA. Skin closure with 2-octyl cyanoacrylate and polyester mesh after primary total knee arthroplasty offers superior cosmetic outcomes and patient satisfaction compared to staples: a prospective trial. Eur J Orthop Surg Traumatol. 2020;30(3):447-53.

21. Sutton N, Schmitz ND, Johnston SS. Economic and clinical comparison of 2-octyl cyanoacrylate/polymer mesh tape with skin staples in total knee replacement. J Wound Care. 2018;27(Sup4):S12-22.

22. Glennie RA, Korczak A, Naudie DD, Bryant DM, Howard JL. MONOCRYL and DERMABOND vs staples in total hip arthroplasty performed through a lateral skin incision: a randomized controlled trial using a patient-centered assessment tool. J Arthroplasty. 2017;32(8):2431-5.

23. Choi KY, Koh IJ, Kim MS, Park DC, Sung YG, In Y. 2-Octyl cyanoacrylate topical adhesive as an alternative to subcuticular suture for skin closure after total knee arthroplasty: a randomized controlled trial in the same patient. J Arthroplasty. 2021;36(9):3141-7.

24. Chalmers BP, Melugin HP, Sculco PK, et al. Characterizing the diagnosis and treatment of allergic contact dermatitis to 2-octyl cyanoacrylate used for skin closure in elective orthopedic surgery. J Arthroplasty. 2017:32(12):3742-7.

25. Chan FJ, Richardson K, Kim SJ. Allergic dermatitis after total knee arthroplasty using the Prineo wound-closure device: a report of three cases. JBJS Case Connect. 2017;7(2):e39.

26. Davis MD, Stuart MJ. Severe allergic contact dermatitis to Dermabond Prineo, a topical skin adhesive of 2-octyl cyanoacrylate increasingly used in surgeries to close wounds. Dermatitis. 2016;27(2):75-6.

27. Durando D, Porubsky C, Winter S, Kalymon J, O'Keefe T, LaFond AA. Allergic contact dermatitis to dermabond (2-octyl cyanoacrylate) after total knee arthroplasty. Dermatitis. 2014;25(2):99-100.

28. Michalowitz A, Comrie R, Nicholas C, Wagner M, Kehoe J. Wound complications after 2-octyl skin closure systems for total joint arthroplasty. J Bone Jt Infect. 2020;5(2):101-5.

29. Ricciardo BM, Nixon RL, Tam MM, Radic RR, Ricciardo BJ. Allergic contact dermatitis to Dermabond Prineo after elective orthopedic surgery. Orthopedics. 2020;43(6):e515-22.

30. Rosen RD, Manna B. Wound dehiscence. Treasure Island, FL: StatPearls Publishing; 2020.

31. Lawson EH, Hall BL, Ko CY. Risk factors for superficial vs deep/organ-space surgical site infections: implications for quality improvement initiatives. JAMA Surg. 2013;148(9):849-58.

32. Domsic RT, Saltzman CL. Ankle osteoarthritis scale. Foot Ankle Int. 1998;19(7):466-71.

33. Wang LS, Wang XY, Tu HT, Huang YF, Qi X, Gao YH. Octyl-2-cyanoacrylate tissue adhesive without subcuticular suture for wound closure after total 
hip arthroplasty: a prospective observational study on thirty-two cases with controls for 3 months follow-up. J Orthop Surg Res. 2020;15(1):467.

34. Bitterman A, Sandhu K. Allergic contact dermatitis to 2-octyl cyanoacrylate after surgical repair: humidity as a potential factor. JAAD Case Rep. 2017;3(6):480-1.

35. Hivnor CM, Hudkins ML. Allergic contact dermatitis after postsurgical repair with 2-octylcyanoacrylate. Arch Dermatol. 2008;144(6):814-5.

36. Lake NH, Barlow BT, Toledano JE, Valentine J, McDonald LS. Contact dermatitis reaction to 2-octyl cyanoacrylate following 3 orthopedic procedures. Orthopedics. 2018;41(2):e289-91.

37. McDonald BS, Buckley DA. Severe dermatitis from Dermabond ${ }^{\circledR}$ surgical glue. Br J Dermatol. 2014;170(3):739-41.

38. Almustafa MA, Ewen AM, Deakin AH, Picard F, Clarke JV, Mahmood FF. Risk factors for surgical site infection following lower limb arthroplasty: a retrospective cohort analysis of 3932 lower limb arthroplasty procedures in a high volume arthroplasty unit. J Arthroplasty. 2018;33(6):1861-7.

39. El-Dars LD, Chaudhury W, Hughes TM, Stone NM. Allergic contact dermatitis to Dermabond after orthopaedic joint replacement. Contact Dermat 2010;62(5):315-7.

40. Gonzalo-Garijo MA, Pérez-Calderón R, Pérez-Rangel I, et al. Contact dermatitis after orthopaedic surgery. Contact Dermat. 2009;61(5):299-300.

41. Lefèvre $S$, Valois A, Truchetet F. Utility of scratch tests for allergic contact dermatitis caused by Dermabond ${ }^{\circledR}$. Contact Dermat. 2017;76(3):193-4.
42. Sachse MM, Junghans T, Rose C, Wagner G. Allergic contact dermatitis caused by topical 2-octyl-cyanoacrylate. Contact Dermat. 2013;68(5):317-9.

43. Duffy C, Zetterlund PB, Aldabbagh F. Radical polymerization of alkyl 2-cyanoacrylates. Molecules. 2018;23(2):465.

44. Bowen C, Bidinger J, Hivnor C, Hoover A, Henning JS. Allergic contact dermatitis to 2-octyl cyanoacrylate. Cutis. 2014;94(4):183-6.

45. Matsumoto T, Parekh SG. Use of negative pressure wound therapy on closed surgical incision after total ankle arthroplasty. Foot Ankle Int. 2015;36(7):787-94.

46. Liu X, Zhang H, Li Y, Chen Y, Deng W, Zhang W. Application of negative pressure wound therapy in total ankle replacement. J Foot Ankle Surg. 2021;60(2):283-7.

47. Tevanov I, Enescu DM, Carp M, Dusca A, Ladaru A, Ulici A. Negative pressure wound therapy in reconstructing extensive leg and foot soft tissue loss in a child: a case study. J Wound Care. 2018;27(Sup6):S14-9.

\section{Publisher's Note}

Springer Nature remains neutral with regard to jurisdictional claims in published maps and institutional affiliations.
Ready to submit your research? Choose BMC and benefit from:

- fast, convenient online submission

- thorough peer review by experienced researchers in your field

- rapid publication on acceptance

- support for research data, including large and complex data types

- gold Open Access which fosters wider collaboration and increased citations

- maximum visibility for your research: over $100 \mathrm{M}$ website views per year

At BMC, research is always in progress.

Learn more biomedcentral.com/submissions 